The systems under discussion are not restricted to plasma membrane; there are articles by O'Malley and other groups on the cytoplasmic steroid receptors, and by Oppenheimer on the nuclear thyroid hormone receptor.

What, then, is wrong with this book? Simply, that $80 \%$ of the articles (all of which were presented as papers at an ICN-UCLA Symposium at Keystone, Colorado, in the spring of 1978) have already been published in vols. 8-10 of the Journal of supramolecular Structure. What the editors of this book have done, encouraged no doubt by Alan Liss, the publisher, is to rearrange these articles a little, add an Author and Subject index, and charge some $£ 35$ (or $£ 52$ if bought, as suggested, through the European book service),- - "a considerable saving in cost," made possible by this duplication. I cannot see any library that subscribes to J. supramol. Struct. buying it, (unless, of course, the library also subscribes to the series entitled Progress in clinical and biological research, of which this book forms volume 31-ahem!). But for those who are not subscribers to the Journal, Transmembrane signalling is a worthwhile purchase.

C. A. Pasternak

\title{
From DNA to protein-the transfer of genetic information
}

\section{By Maria Szekely. 1980. London: Macmillan Press. Pp. 284 . $£ 9.95$.}

It is more than 20 years since Crick first formulated the Central Dogma and, despite the discovery of reverse transcriptase, overlapping genes and split genes, this still accurately describes the flow of information from one molecular species to another. This book contains a detailed account of the processes for the transfer of genetic information as they have been revealed since the Central Dogma was first stated. The author has set herself a formidable task, but has come close to achieving her goal, defeated only by the rapid pace of research and the time taken to publish the book. It is as unfortunate as it is perhaps inevitable that there are very few references to the literature published since 1978.

She has divided her material into three parts, the genetic material, the transcript and the synthesis of proteins. Of these, the two chapters on the genetic material, "The structure of DNA and the structure and organisation of genes" and "Replication of DNA", are the least satisfactory. The first of these chapters contains a mere two paragraphs on the important recent discovery of overlapping genes in viruses and the even more recent discovery of interrupted genes; the latter topic is considered in more detail in chapter 3. The replication of DNA is treated at a much more elementary level than the rest of the material and I sought in vain for consideration of the "unwinding problem" and could find no mention of topoisomerases and of DNA gyrase in particular.

Three excellent chapters cover the process of transcription, the structure of messenger RNA and nucleic acid sequence determination. This latter chapter is especially valuable because of the recent rapid advances that have been made in sequencing methods. It traces the development of these important techniques, from early fingerprinting through copying techniques to direct sequence readout techniques, lucidly and with clear illustrations.

The last three chapters are concerned with the synthesis of proteins and amplify the important role that RNA sequencing has played in our understanding of the ribosome.

This book will be of great value for advanced undergraduate teaching and to postgraduate students and research workers in molecular genetics and related fields. For the medical microbiologist, it provides a current account of the molecular events involved in the transfer of genetic information from DNA to protein, although he may be disappointed that little attention is paid to the action of a wide range of antibiotics that are known to act at specific steps in the process.

S. W. Glover

\section{MCQ tutor for students of microbiology}

By John Gordon. 1978. London: W. Heinemann Medical Books Ltd. Pp. x and 256. $£ 4.50$.

This book records the proceedings of a meeting of 25 scientists in London in September 1978. 